\title{
Preliminary evaluation of GLP-1R PET in the diagnosis and risk stratification of pheochromocytomas
}

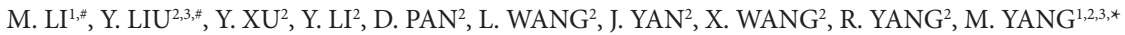 \\ ${ }^{1}$ School of Pharmaceutical Science, Inner Mongolia Medical University, Hohhot 010110, China; ${ }^{2}$ Key Laboratory of Nuclear Medicine, Ministry \\ of Health, Jiangsu Key Laboratory of Molecular Nuclear Medicine, Jiangsu Institute of Nuclear Medicine, Wuxi 214063, China; ${ }^{3}$ The First School \\ of Clinical Medicine, Nanjing Medical University, Nanjing 210029, China
}

${ }^{*}$ Correspondence: yangmin@jsinm.org

${ }^{*}$ Contributed equally to this work.

Received February 27, 2019 / Accepted May 22, 2019

\begin{abstract}
Noninvasive imaging methods for the diagnosis and risk stratification of pheochromocytomas (PHEOs) remain a great clinical challenge. The glucagon-like peptide-1 receptor (GLP-1R) has been validated to be overexpressed in PHEOs and therefore may be a reliable target for PHEOs. In this study, we firstly synthesized a novel radiotracer ${ }^{68} \mathrm{Ga}-\mathrm{NOTA}-\mathrm{MAL}-$ $\mathrm{Cys}^{39}$-exendin- 4 that specifically targets GLP-1R and evaluated the performance of GLP-1R PET for the diagnosis and risk stratification of PHEOs. Cys ${ }^{39}$-exendin-4 was conjugated to NOTA-MAL and then radiolabeled with ${ }^{68} \mathrm{Ga}$. The reaction was completed within 20 min with a yield of $91.6 \pm 2.8 \%$. In vitro cell uptake studies validated its high specificity. PET images showed promising tumor visualization with high uptake $(1.88 \pm 0.10 \% \mathrm{ID} / \mathrm{g}$ for PC-12 poorly differentiated tumors and $1.09 \pm 0.003 \% \mathrm{ID} / \mathrm{g}$ for PC-12 highly differentiated tumors at $30 \mathrm{~min}$ after injection). There was a significant difference in the uptake of ${ }^{68} \mathrm{Ga}-\mathrm{NOTA}-\mathrm{MAL}-\mathrm{Cys}{ }^{39}$-exendin-4 between PC-12 poorly and highly differentiated tumors $(\mathrm{p}<0.001)$, but no significant difference could be observed by ${ }^{18} \mathrm{~F}$-FDG PET. Biodistribution results confirmed the findings of GLP-1R PET and demonstrated that ${ }^{131} \mathrm{I}-\mathrm{MIBG}$ couldn't be used for the risk stratification of PHEOs. Immunohistochemistry (IHC) staining revealed differences in GLP-1R expression between PC-12 poorly and highly differentiated tumor tissues. These results demonstrated that ${ }^{68} \mathrm{Ga}-\mathrm{NOTA}-\mathrm{MAL}-\mathrm{Cys}^{39}$-exendin-4 could specifically target GLP-1R with favorable pharmacokinetic properties. GLP-1R PET can be used for PHEOs detection and has potential for the risk stratification of PHEOs.
\end{abstract}

Key words: glucagon-like peptide-1 receptor (GLP-1R), pheochromocytomas (PHEOs), PET; 68Ga, Exendin-4

Pheochromocytomas (PHEOs) are catecholaminesecreting neuroendocrine tumors (NETs) arising in the adrenal medulla. Patients are usually diagnosed with malignant PHEOs after the formation of irreversible disease due to the absence of reliable molecular or histological markers for malignancy. However, the overall prognosis and five-year survival rates of malignant PHEOs is poor [1-4]. In addition, many other clinical conditions may also produce symptoms similar to catecholamine overdose caused by malignant PHEOs, making the differential diagnosis difficult [5]. Since invasive procedures for PHEOs is prohibited in most cases [6], the currently used diagnostic methods in clinical practice are biochemical examinations and imaging techniques.

A variety of non-specific biomarkers and hormones can be used as indicators for the diagnosis of PHEOs, but the lack of specificity and lots of interference limit their application [7-9]. Anatomic imaging such as CT and MRI are applicable to the lesions with tumor diameter less than $5 \mathrm{~cm}$, but these tumors are confined to the adrenal gland and less likely to metastasize [10]. For the lesions larger than $5 \mathrm{~cm}$, especially in patients with metastatic disease, functional imaging such as PET or SPECT using radiotracers are necessary and can provide large benefits in the evaluation of disease extent, staging and therapy decision making [11]. Although several radiotracers such as ${ }^{131} \mathrm{I} /{ }^{123} \mathrm{I}-\mathrm{MIBG},{ }^{18} \mathrm{~F}-\mathrm{FDG},{ }^{18} \mathrm{~F}$-FDOPA and ${ }^{68} \mathrm{Ga}$-DOTA-TATE [12-14] can be used for PHEOs detection, none of them can be a gold standard and the optimal application conditions for each tracer are different [15]. Therefore, there are still obstacles needed to be solved in the noninvasive diagnosis of PHEOs.

Another urgent clinical requirement for PHEOs is the risk stratification since the clinical course of malignant PHEOs is significantly variable and individualized approaches to malignant patients are necessary [16]. Recently, a scoring 
system was developed by pathologists, in which malignant PHEOs are graded as low, intermediate, or high risk of metastases based on the degree of differentiation [17]. The five-year survival rates are $100 \%, 67 \%$, and $22 \%$ for well, moderately, and poorly differentiated PHEOs, respectively [18]. However, there is still a lack of noninvasive imaging methods for the risk stratification of PHEOs.

The glucagon-like peptide-1 (GLP-1) is an endogenous insulin tropic peptide secreted from gastrointestinal tract. Recent studies showed that GLP-1 receptor (GLP-1R) was massively overexpressed in PHEOs and GLP-1 could promote the differentiation of PC-12 cells [19]. Therefore, GLP-1R may be a potential target for PHEOs. In our previous studies, we synthesized ${ }^{18} \mathrm{~F}$-FBEM and labeled it with Cys ${ }^{39}$-exendin-4, which has been validated a GLP-1 analog. Preclinical experiments demonstrated that ${ }^{18} \mathrm{~F}-\mathrm{FBEM}-\mathrm{Cys}{ }^{39}$-exendin- 4 could be a promising radiotracer for insulinoma with high yield, low abdominal background and good image contrast [20]. In order to reduce the radioactive uptake in abdomen to provide better image properties and simplify the synthetic steps to facilitate the clinical application, we designed a one-step method to synthesize ${ }^{18} \mathrm{~F}-\mathrm{Al}-\mathrm{NOTA}-\mathrm{MAL}-\mathrm{Cys}{ }^{39}$-exendin-4. This labeling process took only $30 \mathrm{~min}$ and the final product did not require further purification. We then validated the characteristics of ${ }^{18} \mathrm{~F}$-Al-NOTA-MAL-Cys ${ }^{39}$-exendin-4 such as high specificity and low abdominal uptake, and demonstrated its reliable diagnostic performance in diabetes, insulinoma and prostate cancer [21-23]. In this present study, we intend to develop another novel radiotracer using positron nuclide ${ }^{68} \mathrm{Ga}$. Compared to ${ }^{18} \mathrm{~F},{ }^{68} \mathrm{Ga}$ has a shorter half-life and lower effective radiation dose, besides, ${ }^{68} \mathrm{Ga}$ can be obtained from the ${ }^{68} \mathrm{Ge} /{ }^{68} \mathrm{Ga}$ generator and the labeling is much more convenient. In summary, high availability, low price and short half-life, make ${ }^{68} \mathrm{Ga}$ one of the most popular new radionuclides and have great potential for clinical application [24].

Taken together, radiotracers targeting GLP-1R appear to have potential in the detection of PHEOs. In this study, we intend to use ${ }^{68} \mathrm{Ga}$-NOTA-MAL-Cys ${ }^{39}$-exendin-4 to evaluate the feasibility of GLP-1R PET imaging in the diagnosis and risk stratification of PHEOs.

\section{Materials and methods}

Preparation of radiotracers. $\mathrm{Cys}^{39}$-exendin-4 was purchased from Apeptide Co., Ltd (Shanghai, China). NOTA-MAL was purchased from CheMatech (Dijon, France). ${ }^{68} \mathrm{Ge} /{ }^{68} \mathrm{Ga}$ generator (ITG, Germany) was provided by Jiangsu Institute of Nuclear Medicine. The analysis of peptides and final radiolabeled exendin-4 was accomplished using HPLC and LC-MS systems. The protocol of HPLC and LC-MS has been described in our previous reports [20, 21].

The synthesis scheme of NOTA-MAL-Cys ${ }^{39}$-exendin-4 and ${ }^{131} \mathrm{I}-\mathrm{MIBG}$ have been described elsewhere $[25,26] .{ }^{18} \mathrm{~F}-\mathrm{FDG}$ was generously donated by Wuxi Fourth People's Hospital and has reached the level of clinical application. $\left[{ }^{68} \mathrm{Ga}\right] \mathrm{GaCl}_{3}$ was eluted from a ${ }^{68} \mathrm{Ge} /{ }^{68} \mathrm{Ga}$-generator with $0.05 \mathrm{M} \mathrm{HCl}$, and NOTA-MAL-Cys ${ }^{39}$-exendin-4 was then radiolabeled with ${ }^{68} \mathrm{Ga}^{3+}$. In brief, $0.375 \mathrm{ml} \mathrm{NaAc}(0.1 \mathrm{M})$ was added into $1.5 \mathrm{~mL}$ $\left[{ }^{68} \mathrm{Ga}\right] \mathrm{GaCl}_{3}$ solution, followed by the addition of $100 \mu \mathrm{g}$ NOTA-MAL-Cys ${ }^{39}$-exendin-4 and then heating at $100^{\circ} \mathrm{C}$ for $10 \mathrm{~min}$. After cooling to room temperature, the reacted mixture was diluted with sterile water and injected onto an active Varian Bond Elut C18 column. The column was eluted twice by $10 \mathrm{ml}$ sterile water and then eluted with $0.3 \mathrm{ml}$ of $10 \mathrm{mM} \mathrm{HCl}$ in ethanol to get the final product.

Cell culture and animal models. The PC-12 poorly and highly differentiated cells from rat adrenal medulla cell lines and SKOV3 cells were obtained from the Cell Bank in Shanghai Institute of Cell Biology, China. The cells were cultured in RPMI-1640 medium supplemented with 10\% fetal bovine serum and in a humidified atmosphere containing $5 \% \mathrm{CO}_{2}$ at $37^{\circ} \mathrm{C}$. To establish xenograft tumor models, male $\mathrm{BALB} / \mathrm{c}$ nude mice (SLAC Laboratory Animal Co., Ltd, China) aged 5-6 weeks were injected with $5 \times 10^{6}$ SKOV3, PC-12 poorly differentiated, or PC-12 highly differentiated cells in their right armpits, respectively. The mice were used when the tumor volume reached about $200 \mathrm{~mm}^{3}$. The mice were housed under standard condition in the animal center of Jiangsu Institute of Nuclear Medicine and animal experiments were approved by the local animal welfare committee.

In vitro cell uptake studies. Cell uptake studies were performed with reference to our previous reports [27]. PC-12 poorly or highly differentiated cells were seeded in $\gamma$-counter tubes at a density of $1 \times 10^{6}$ cells per tube, then washed twice with PBS and incubated with ${ }^{68} \mathrm{Ga}-\mathrm{NOTA}-\mathrm{MAL}-\mathrm{Cys}^{39}$ exendin-4 (54 KBq/tube) at $37^{\circ} \mathrm{C}$ for $30 \mathrm{~min}, 60 \mathrm{~min}$, and $120 \mathrm{~min}$, respectively. For blocking studies, unlabeled Cys ${ }^{39}{ }_{-}$ exendin- 4 was added to each tube at a final concentration of $2 \mu \mathrm{M}$. After incubation, the cells were washed and extracted. Radioactivity was measured in a $\gamma$-counter. All the experiments were repeated at least twice with triplicate wells.

Pharmacokinetics in blood. For pharmacokinetic tests, six normal mice (5-6 weeks old) were intravenously injected with ${ }^{68} \mathrm{Ga}$-NOTA-MAL-Cys ${ }^{39}$-exendin-4 $(\sim 100 \mu \mathrm{Ci})$ in the tail, and the blood $(10 \mu \mathrm{l})$ was collected at $5 \mathrm{~min}, 10$ $\mathrm{min}, 15 \mathrm{~min}, 20 \mathrm{~min}, 30 \mathrm{~min}, 45 \mathrm{~min}, 60 \mathrm{~min}, 90 \mathrm{~min}$, and $120 \mathrm{~min}$ after injection, respectively. The concentration of ${ }^{68} \mathrm{Ga}$-NOTA-MAL-Cys ${ }^{39}$-exendin-4 in blood was calculated based on the radioactivity measured by a $\gamma$-counter after all samples were weighed. DAS2.0 software was used with a two-compartmental open model to analyze the pharmacokinetic parameters.

MicroPET imaging. MicroPET scans were performed using an Inveon microPET system (Siemens Medical Solutions) in Jiangsu Institute of Nuclear Medicine. Six PC-12 poorly differentiated and six PC-12 highly differentiated tumor-bearing mice were intravenously injected with ${ }^{68} \mathrm{Ga}$-NOTA-MAL-Cys ${ }^{39}$-exendin-4 $(\sim 100 \mu \mathrm{Ci})$ in the tail. In addition, to explore whether different degrees of differentiated PHEOs could be identified by ${ }^{18} \mathrm{~F}-\mathrm{FDG}$ PET, another six 
PC-12 poorly differentiated and six PC- 12 highly differentiated mice were intravenously injected with ${ }^{18} \mathrm{~F}-\mathrm{FDG}(\sim 100$ $\mu \mathrm{Ci})$. Static PET images were acquired at $30 \mathrm{~min}, 60 \mathrm{~min}$, and $120 \mathrm{~min}$ after injection of ${ }^{68} \mathrm{Ga}-\mathrm{NOTA}-\mathrm{MAL}-\mathrm{Cys}{ }^{39}$ exendin- 4 or ${ }^{18} \mathrm{~F}-\mathrm{FDG}$, respectively. To further demonstrate the specificity of ${ }^{68} \mathrm{Ga}$-NOTA-MAL-Cys ${ }^{39}$-exendin- 4 for the diagnosis of PHEOs, we additionally performed GLP-1R PET imaging on four SKOV3 tumor-bearing mice $60 \mathrm{~min}$ after intravenous injection of ${ }^{68} \mathrm{Ga}-\mathrm{NOTA}-\mathrm{MAL}-\mathrm{Cys}^{39}$-exendin-4 $(\sim 100 \mu \mathrm{Ci})$. All images obtained were reconstructed using 3-dimensional ordered subsets expectation maximum algorithm (3D-OSEM). The imaging-derived percentage injected dose per gram $(\% \mathrm{ID} / \mathrm{g})$ of regions of interest (ROIs) over the tumor and major organs were calculated on decaycorrected whole-body coronal images using vendor software ASI Pro 6.7.1.1.

Biodistribution studies. For ex vivo biodistribution studies, PC-12 poorly and highly differentiated tumorbearing mice were sacrificed immediately at $30 \mathrm{~min}, 60 \mathrm{~min}$, and $120 \mathrm{~min}$ after intravenous injection of ${ }^{68} \mathrm{Ga}$-NOTA-MAL$\mathrm{Cys}^{39}$-exendin-4 ( $100 \mu \mathrm{Ci}, \mathrm{n}=6 /$ group $)$. Besides, in order to evaluate whether there were differences in the biodistribution of ${ }^{131} \mathrm{I}-\mathrm{MIBG}$ and ${ }^{68} \mathrm{Ga}$-NOTA-MAL-Cys ${ }^{39}$-exendin-4 in tumor tissues and other organs, another PC-12 poorly and highly differentiated mice were sacrificed at $60 \mathrm{~min}$ after intravenous injection of ${ }^{131} \mathrm{I}-\mathrm{MIBG}(\sim 20 \mu \mathrm{Ci}, \mathrm{n}=6$ /group $)$. Tumors and major organs of all mice were removed and the radioactivity was determined by a $\gamma$-counter after weighed. The radioactivity uptakes in the tumors and organs were expressed as $\% \mathrm{ID} / \mathrm{g}$ as mentioned above.

Western blot analysis. The frozen stored SKOV3, PC-12 poorly differentiated, and $\mathrm{PC}-12$ highly differentiated tumors harvested from tumor-bearing mice were lysed with lysis buffer. Protein levels were quantified using the enhanced BCA protein assay kit. Whole cell lysates containing equivalent amount of protein were separated by SDS-PAGE and then incubated overnight with primary antibody. Goat polyclonal antibodies against GLP-1R (Abcam, San Francisco, CA) and $\beta$-actin (Abcam, San Francisco, CA) were used as the primary antibody. The HRP-labeled donkey anti-goat $\operatorname{IgG}(\mathrm{H}+\mathrm{L})$ and goat anti-mouse $\operatorname{IgG}(\mathrm{H}+\mathrm{L})$ (Beyotime, China) were used as secondary antibody.

Immunohistochemistry examinations. For immunohistochemistry (IHC), three PC-12 poorly differentiated and three PC-12 highly differentiated tumor-bearing mice were sacrificed, the tumors were removed and immediately put into formalin for further experiments. Tumor biopsies from tumor-bearing mice were fixed in paraffin and the process of GLP-1R staining has been described before [22]. In brief, GLP-1R staining was performed on consecutive $4 \mathrm{~mm}$ sections from each biopsy using rabbit monoclonal antibody 2993-1 from Epitomics (USA) as the primary antibody and Power-Stain $^{\text {tw }}$ 1.0 Polymer Peroxidase System (mouse/rabbit $\operatorname{IgG})$ as the secondary antibody. All sections were counterstained with diaminophenylazine. Six fields of view were randomly selected from each section and observed using an optical microscope (Olympus).

Statistical analysis. All data were expressed as means \pm standard deviation (SD). Means were compared using student $\mathrm{t}$ test, and $\mathrm{p}$-value $<0.05$ were considered statistically significant. All statistical analysis was performed on IBM SPSS 22.0 and all figures were created by Origin 8.5.

\section{Results}

Chemistry and radiolabeling. NOTA-MAL-Cys ${ }^{39}$-exendin- 4 was synthesized by the reaction of $\mathrm{Cys}^{39}$-exendin- 4 with NOTA-MAL. The yield was around $70 \%$ and MS measured $\mathrm{m} / \mathrm{z} 4625.92$ for $[\mathrm{MH}]^{+}\left(\mathrm{C}_{202} \mathrm{H}_{309} \mathrm{~N}_{55} \mathrm{O}_{66} \mathrm{~S}_{2}\right.$, calculated molecular weight, 4626). The synthesis scheme of ${ }^{68}$ Ga-NOTA-MAL-Cys ${ }^{39}$-exendin-4 is shown in Figure 1 and the reaction was completed within $20 \mathrm{~min}$ with a yield of $91.6 \pm 2.8 \%$. The analytic HPLC results are shown in Figure $2 \mathrm{~A}$, from which we can see that the elution time was $23 \mathrm{~min}$. The final radiochemical purity was higher than $95 \%$ while the specific activity was at least $8.5 \mathrm{GBq} / \mu \mathrm{mol}$.

In vitro cell uptake studies. The cell uptake and blocking results of ${ }^{68} \mathrm{Ga}$-NOTA-MAL-Cys ${ }^{39}$-exendin-4 are shown in Figure $2 \mathrm{~B}$. From which we can identify that the uptake of both PC-12 poorly and highly differentiated cells reached plateau at $30 \mathrm{~min}$ and remained up to $120 \mathrm{~min}$, among them PC-12 poorly differentiated cells reached $1.84 \pm 0.21 \% \mathrm{AD}$ at $30 \mathrm{~min}$ while PC-12 highly differentiated cells reached $0.90 \pm 0.07 \% \mathrm{AD}$ at the same time. A significant difference could be calculated between these two groups $(p<0.01)$. With the presence of excess Cys ${ }^{39}$-exendin- 4 , the uptake of PC-12 poorly and highly differentiated cells decreased to $0.47 \pm 0.02$ $\% \mathrm{AD}$ and $0.24 \pm 0.10 \% \mathrm{AD}$ at $30 \mathrm{~min}$, respectively $(\mathrm{p}<0.05)$.

Pharmacokinetics in blood. The concentration-time curve of ${ }^{68} \mathrm{Ga}$-NOTA-MAL-Cys ${ }^{39}$-exendin-4 are shown in Figure 2C. After intravenous injection in the tail of normal mice, the concentration of the tracer showed a logarithmic decrease and was almost zero at $120 \mathrm{~min}$. The distribution half-life $\left(\mathrm{t}_{1 / 2 \alpha}\right)$ of ${ }^{68} \mathrm{Ga}-\mathrm{NOTA}-\mathrm{MAL}-\mathrm{Cys} \mathrm{s}^{39}$-exendin-4 was 3.16 min while the elimination half-life $\left(\mathrm{t}_{1 / 2 \beta}\right)$ was $14.52 \mathrm{~min}$.

MicroPET imaging. The representative microPET images of the uptake of ${ }^{68} \mathrm{Ga}$-NOTA-MAL-Cys ${ }^{39}$-exendin-4 or ${ }^{18} \mathrm{~F}-\mathrm{FDG}$ in both PC-12 poorly and highly differentiated tumor-bearing mice at $30 \mathrm{~min}, 60 \mathrm{~min}$ and $120 \mathrm{~min}$ after injection are shown in Figure 3. The quantitative results of the radioactivity in the tumor and major organs determined by ROIs are shown in Figure 4. After intravenous injection of both ${ }^{68} \mathrm{Ga}$-NOTA-MAL-Cys ${ }^{39}$-exendin-4 and ${ }^{18} \mathrm{~F}$-FDG, there was rapid and obvious accumulation of radioactivity in both PC-12 poorly and highly differentiated tumors. The tumor uptake of ${ }^{68} \mathrm{Ga}$-NOTA-MAL-Cys ${ }^{39}$-exendin-4 at $30 \mathrm{~min}$ was higher than that of $60 \mathrm{~min}$ and $120 \mathrm{~min}$ in both PC-12 poorly and highly differentiated tumor-bearing mice, while the tumor uptake of ${ }^{18} \mathrm{~F}-\mathrm{FDG}$ didn't show such big difference at different time points. More importantly, at each time point, 
His-Gly-Glu-Gly-Thr-Phe-Thr-Ser-Asp-Leu-Ser-Lys-GIn-Met-Glu-Glu-Glu-Ala-Val-Arg-Leu-Phe-IleGlu-Trp-Leu-Lys-Asn-Gly-Gly-Pro-Ser-Ser-Gly-Ala-Pro-Pro-Pro-Cys-NH 2

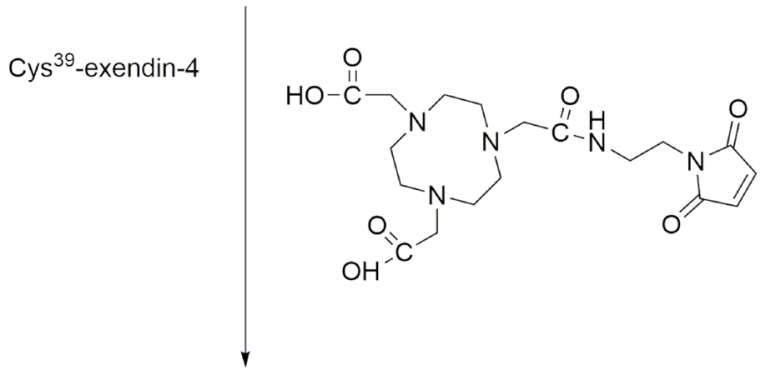

His-Gly-Glu-Gly-Thr-Phe-Thr-Ser-Asp-Leu-Ser-Lys-GIn-Met-Glu-Glu-Glu-Ala-Val-Arg-Leu-Phe-IleGlu-Trp-Leu-Lys-Asn-Gly-Gly-Pro-Ser-Ser-Gly-Ala-Pro-Pro-Pro-NH

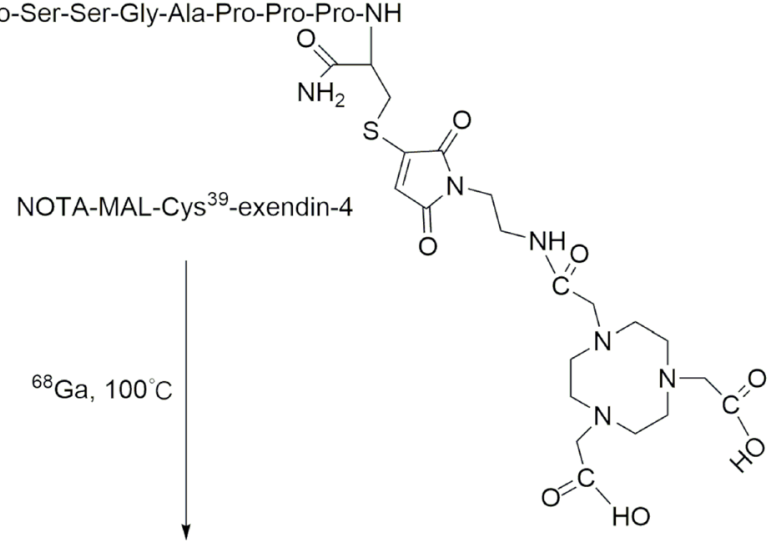

His-Gly-Glu-Gly-Thr-Phe-Thr-Ser-Asp-Leu-Ser-Lys-Gln-Met-Glu-Glu-Glu-Ala-Val-Arg-Leu-Phe-lleGlu-Trp-Leu-Lys-Asn-Gly-Gly-Pro-Ser-Ser-Gly-Ala-Pro-Pro-Pro-NH

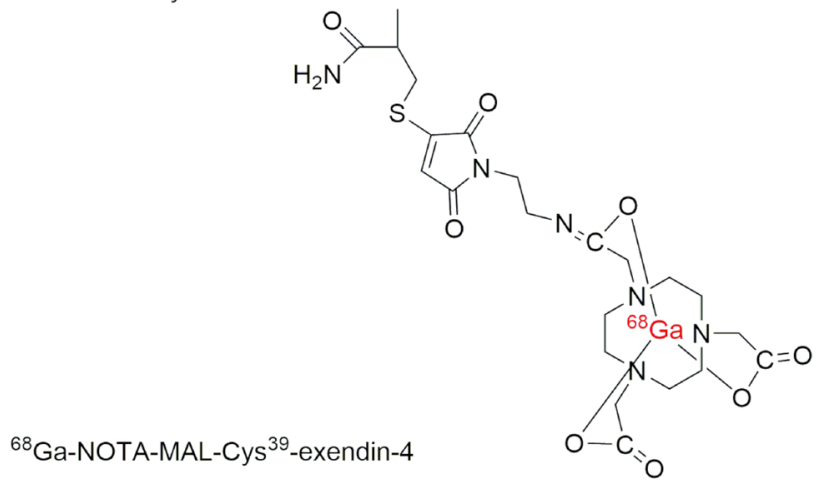

Figure 1. The synthesis scheme of ${ }^{68}$ Ga-NOTA-MAL-Cys ${ }^{39}$-exendin-4.

the tumor uptake of ${ }^{68} \mathrm{Ga}-\mathrm{NOTA}-\mathrm{MAL}-\mathrm{Cys}^{39}$-exendin-4 was significantly different between PC-12 poorly and highly differentiated tumors $(\mathrm{p}<0.001)$, however, no difference in ${ }^{18} \mathrm{~F}-\mathrm{FDG}$ uptakes between these two types of tumors could be observed ( $p>0.05)$.

In addition, after intravenous injection of ${ }^{68} \mathrm{Ga}$-NOTAMAL-Cys ${ }^{39}$-exendin-4, there was no such evident difference of the radioactivity in major organs between PC-12 poorly and highly differentiated tumor-bearing mice. In detail, at 30 min after injection, the radioactivity of $\mathrm{PC}-12$ poorly differentiated group in tumor, heart, liver, bone, muscle, and kidney were $1.88 \pm 0.10 \% \mathrm{ID} / \mathrm{g}, 0.53 \pm 0.06 \% \mathrm{ID} / \mathrm{g}, 0.53 \pm 0.08 \% \mathrm{ID} / \mathrm{g}$, $0.51 \pm 0.06 \% \mathrm{ID} / \mathrm{g}, 0.22 \pm 0.03 \% \mathrm{ID} / \mathrm{g}$, and $71.11 \pm 11.89 \% \mathrm{ID} / \mathrm{g}$, respectively, while the radioactivity of PC-12 highly differentiated group in tumor, heart, liver, bone, muscle, and kidney were $1.09 \pm 0.003 \% \mathrm{ID} / \mathrm{g}, 0.43 \pm 0.05 \% \mathrm{ID} / \mathrm{g}, 0.56 \pm 0.09 \% \mathrm{ID} / \mathrm{g}$, $0.53 \pm 0.15 \% \mathrm{ID} / \mathrm{g}, 0.14 \pm 0.04 \% \mathrm{ID} / \mathrm{g}$, and $57.47 \pm 8.79 \% \mathrm{ID} / \mathrm{g}$, respectively. In order to further validate the specificity of ${ }^{68} \mathrm{Ga}-\mathrm{NOTA}-\mathrm{MAL}-\mathrm{Cys}{ }^{39}$-exendin-4 for the diagnosis of PHEOs, we performed the GLP-1R PET on SKOV3 tumor bearing mice. The quantitative results of GLP-1R PET in three types of tumors at $60 \mathrm{~min}$ after intravenous injection of 

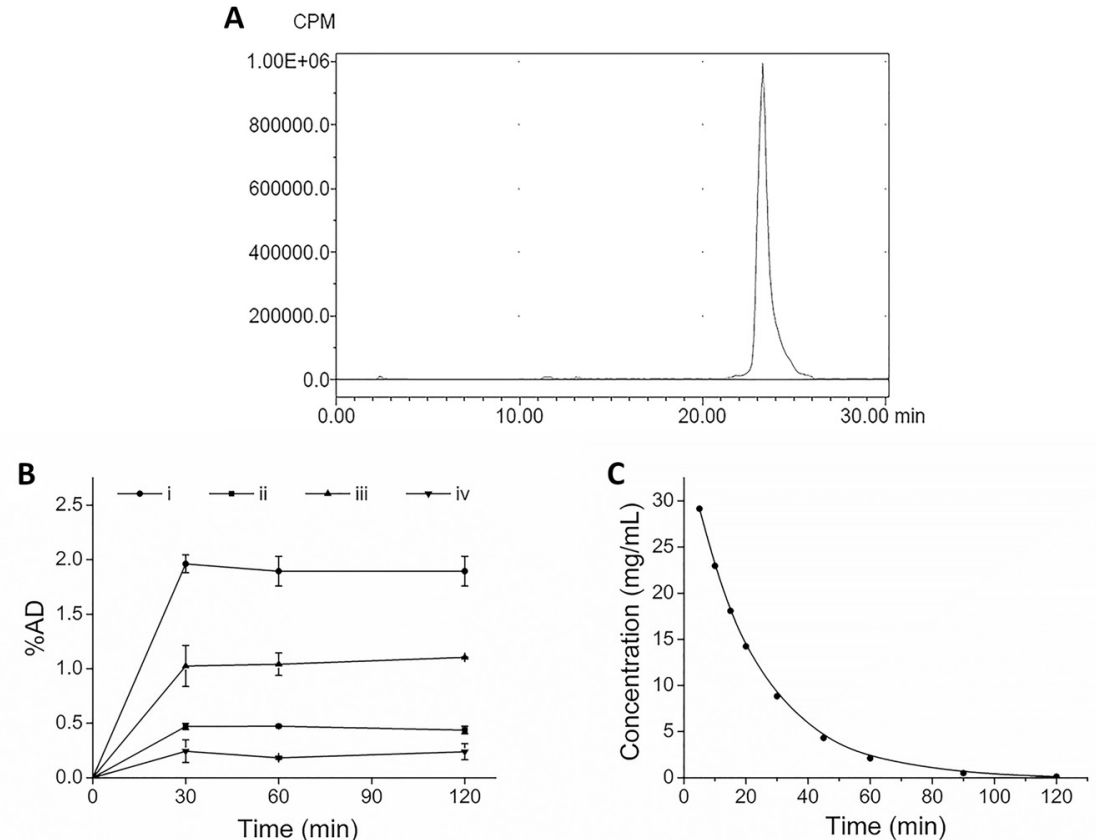

Figure 2. The characteristics of ${ }^{68}$ Ga-NOTA-MAL-Cys ${ }^{39}$-exendin-4. A) Radio-HPLC chromatograms of ${ }^{68}$ Ga-NOTA-MAL-Cys ${ }^{39}$-exendin-4. B) Cell uptake assay of ${ }^{68} \mathrm{Ga}-\mathrm{NOTA}-\mathrm{MAL}-\mathrm{Cys}{ }^{39}$-exendin-4 in PC-12 poorly and highly differentiated cells. i: Total uptake of PC-12 poorly differentiated cells; ii: Block of PC-12 poorly differentiated cells; iii: Total uptake of PC-12 highly differentiated cells; iv: Block of PC-12 highly differentiated cells. C) Pharmacokinetics of ${ }^{68}$ Ga-NOTA-MAL-Cys ${ }^{39}$-exendin-4 in blood $(n=6)$.

A

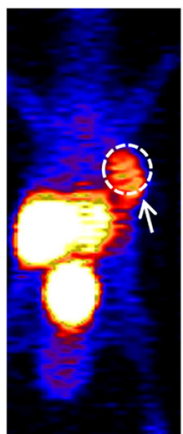

$30 \mathrm{~min}$

C

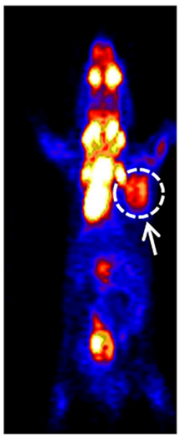

$30 \mathrm{~min}$

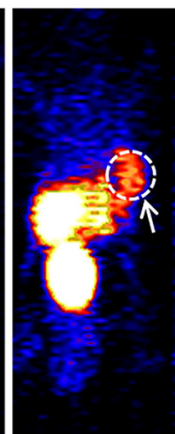

$60 \mathrm{~min}$

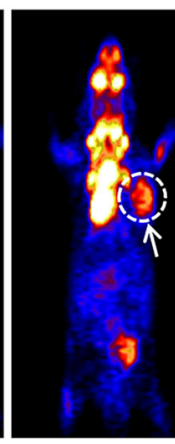

$60 \mathrm{~min}$

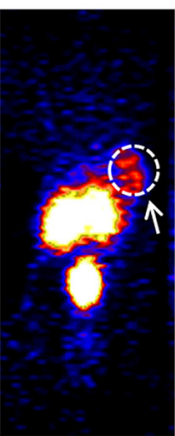

$120 \mathrm{~min}$

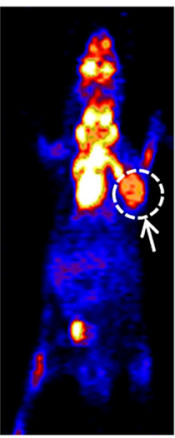

120 min
B

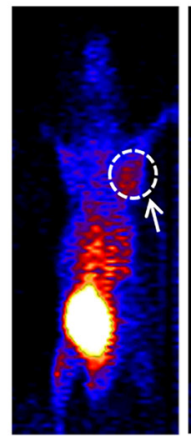

$30 \mathrm{~min}$

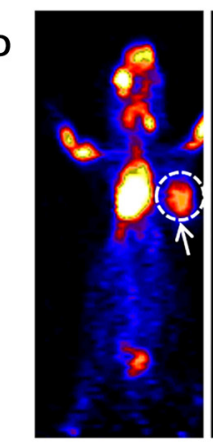

$30 \mathrm{~min}$

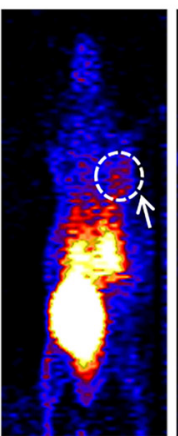

$60 \mathrm{~min}$

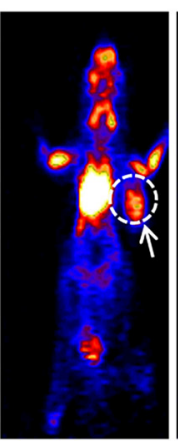

$60 \mathrm{~min}$

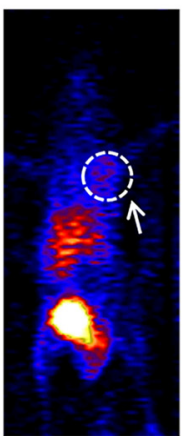

$120 \mathrm{~min}$

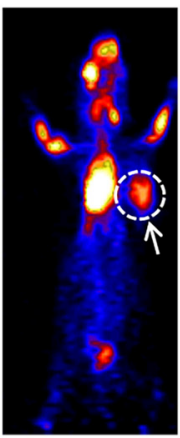

$120 \mathrm{~min}$

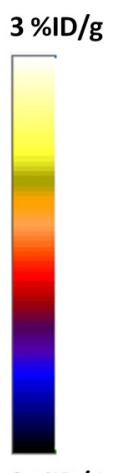

$0 \% \mathrm{ID} / \mathrm{g}$

$15 \%$ ID/g

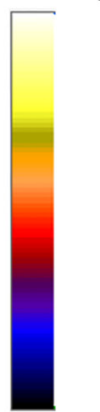

$0 \% \mathrm{ID} / \mathrm{g}$

Figure 3. Representative microPET images at $30 \mathrm{~min}, 60 \mathrm{~min}$ and $120 \mathrm{~min}$ after intravenous injection. ${ }^{68} \mathrm{Ga}-\mathrm{NOTA}-\mathrm{MAL}-\mathrm{Cys} \mathrm{s}^{39}$-exendin-4 in PC-12 poorly (A) and highly (B) differentiated tumor-bearing mice (n=6/group). ${ }^{18} \mathrm{~F}-\mathrm{FDG}$ in PC-12 poorly (C) and highly (D) differentiated tumor-bearing mice ( $n=6 /$ group). 

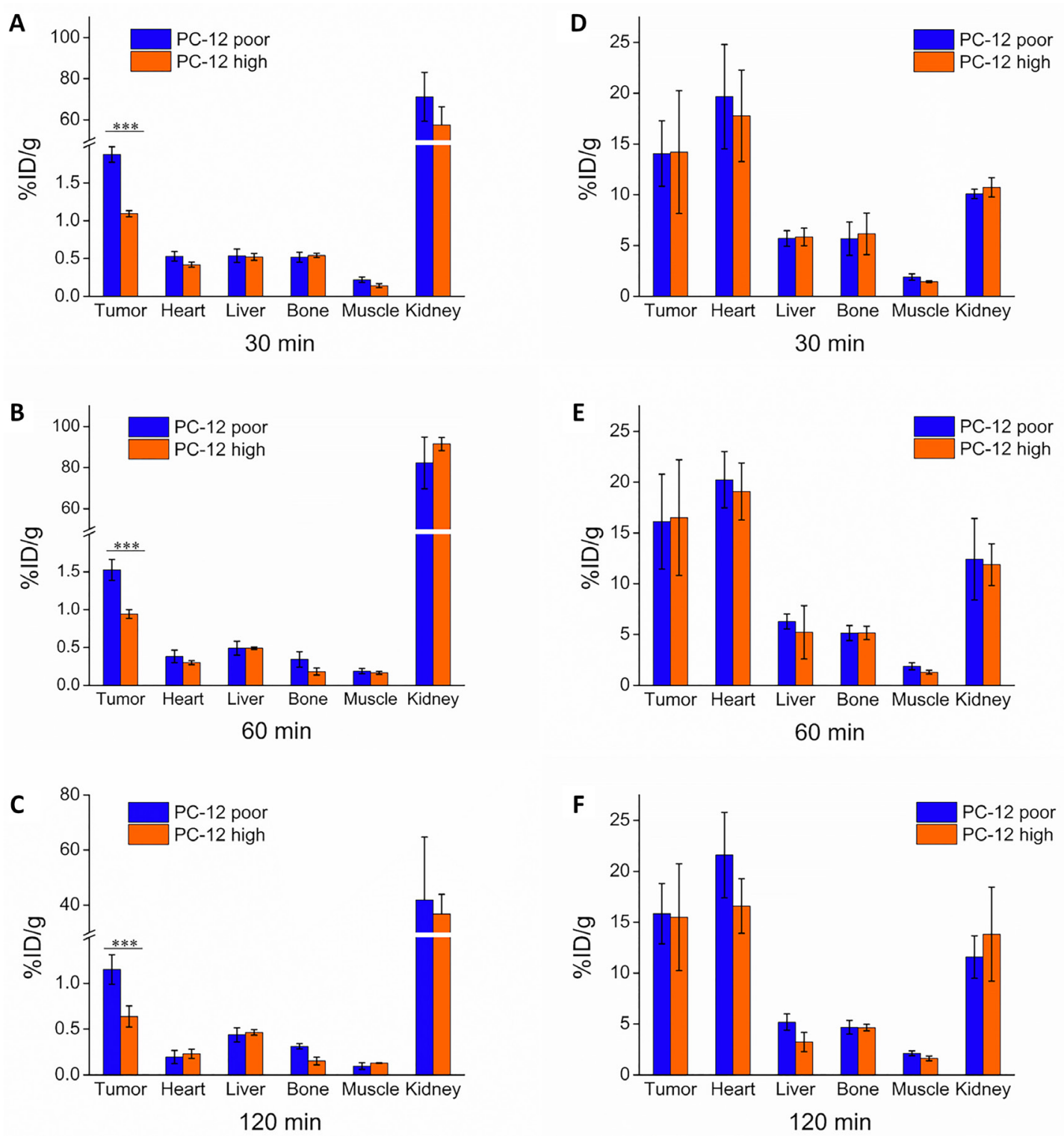

Figure 4. The results of quantitative uptake of radiotracers. Quantitative uptake of ${ }^{68}$ Ga-NOTA-MAL-Cys ${ }^{39}$-exendin-4 (A-C) and ${ }^{18}$ F-FDG (D-F) in tumor and major organs of $\mathrm{PC}-12$ poorly and highly differentiated tumor-bearing mice $(\mathrm{n}=6 /$ group$) .{ }^{* *} \mathrm{p}<0.001$

radiotracer are shown in Figure 5A. The uptake of radioactivity in PC-12 poorly and highly differentiated tumors were significantly higher than that in SKOV3 tumors $(\mathrm{p}<0.001)$ and the SKOV 3 tumors couldn't be found using GLP-1R PET due to too low tumor uptake.

Biodistribution studies. The biodistribution results of ${ }^{68} \mathrm{Ga}$-NOTA-MAL-Cys ${ }^{39}$-exendin-4 in tumor and major organs of PC-12 poorly and highly differentiated tumorbearing mice at $30 \mathrm{~min}, 60 \mathrm{~min}$, and $120 \mathrm{~min}$ after injection are shown in Table 1 . There was a significant difference in tumor uptake between PC-12 poorly and highly differentiated groups, which was consistent with the results of microPET imaging. The radiotracer cleared quickly from blood and major organs such as heart, liver and bone. The tumor to muscle and liver ratios were high in both two groups at $60 \mathrm{~min}$. The radioactivity in most organs and tissues was low and slightly higher in GLP-1R positive organs such as pancreas. However, the kidney uptake was much higher than in any other organs. The biodistribution results of ${ }^{131} \mathrm{I}-\mathrm{MIBG}$ at $60 \mathrm{~min}$ after intravenous injection are also shown in Table 1. Obviously, no significant difference in PC-12 poorly and highly differentiated groups could be identified.

Western blot analysis and immunohistochemistry examinations. The results of western blot in SKOV3, PC-12 poorly differentiated, and PC-12 highly differentiated tumors 
are shown in Figures 5B and 5C. Similar to the microPET results, the expression of GLP-1R was higher in PC-12 poorly differentiated tumors than that in PC-12 highly differentiated tumors and the SKOV3 tumors showed nearly no expression of GLP-1R. The expression of GLP-1R in PC-12 poorly and highly differentiated tumors was also evaluated by IHC, and the representative images are shown in Figure 6. The results indicated that the GLP-1R expression in PC-12 poorly differentiated tumor tissues was higher than that in PC-12 highly differentiated tumor tissues. And HE staining results showed that there was no significant change of the morphology in tumor tissues between these two groups.

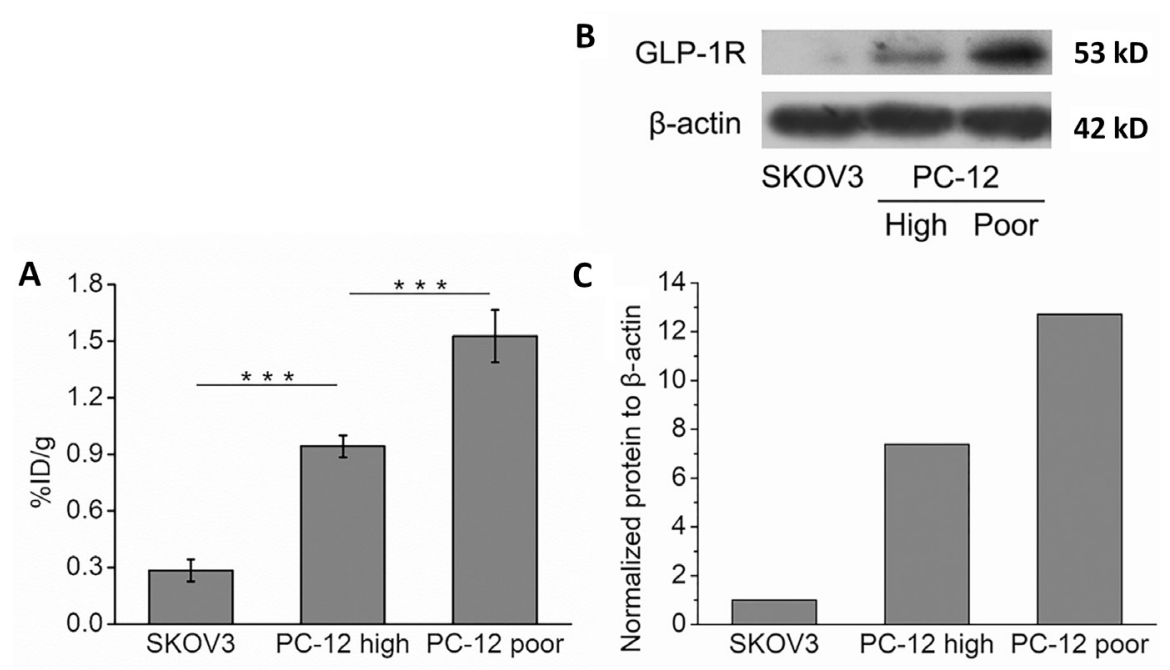

Figure 5. The microPET and western blot results in three types of tumors. Quantitative results of ${ }^{68} \mathrm{Ga}-\mathrm{NOTA}-\mathrm{MAL}-\mathrm{Cys} \mathrm{s}^{39}$-exendin-4 uptake in SKOV3 $(n=4)$, PC-12 poorly differentiated $(n=6)$, and $P C-12$ highly differentiated $(n=6)$ tumors at 60 min after intravenous injection $(A)$. Western blot analysis of three types of tumors ( $n=1 /$ group) $(B$ and $C) .{ }^{* * *} p<0.001$

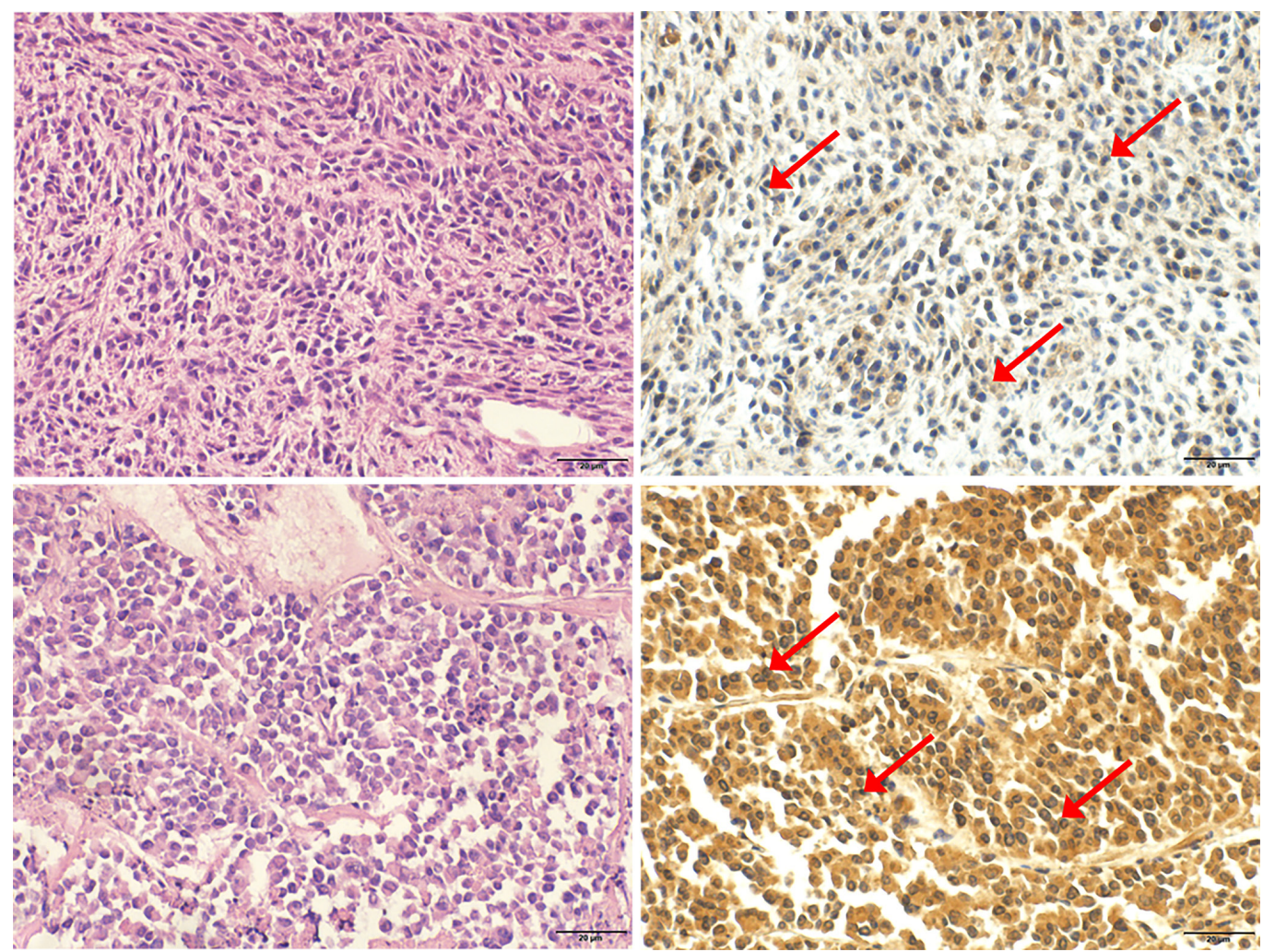

Figure 6. The results of immunohistochemistry. Representative images (40×) of HE staining (left) and GLP-1R staining (right) in PC-12 poorly (bottom) and highly (top) differentiated tumor tissues ( $n=3 /$ group). GLP-1R positive regions are indicated by arrows. 
Table 1 Biodistribution results of ${ }^{68} \mathrm{Ga}$-NOTA-MAL-Cys ${ }^{39}$-exendin-4 and ${ }^{131} \mathrm{I}-\mathrm{MIBG}$ in PC-12 poorly and highly differentiated tumor-bearing mice at various time after injection ( $n=6 /$ group).

\begin{tabular}{|c|c|c|c|c|c|c|c|c|}
\hline \multirow{3}{*}{ Parameters } & \multicolumn{6}{|c|}{${ }^{68}$ Ga-NOTA-MAL-Cys ${ }^{39}$-exendin-4 (\%ID/g) } & \multicolumn{2}{|c|}{${ }^{131}$ I-MIBG (\%ID/g) } \\
\hline & \multicolumn{3}{|c|}{ PC-12 poor } & \multicolumn{3}{|c|}{ PC-12 high } & \multirow{2}{*}{$\frac{\text { PC-12 poor }}{60 \mathrm{~min}}$} & \multirow{2}{*}{$\begin{array}{c}\text { PC-12 high } \\
60 \mathrm{~min} \\
\end{array}$} \\
\hline & $30 \mathrm{~min}$ & $60 \mathrm{~min}$ & $120 \mathrm{~min}$ & $30 \mathrm{~min}$ & $60 \mathrm{~min}$ & $120 \mathrm{~min}$ & & \\
\hline Blood & $0.89 \pm 0.12$ & $0.56 \pm 0.17$ & $0.21 \pm 0.06$ & $0.98 \pm 0.11$ & $0.62 \pm 0.26$ & $0.40 \pm 0.02$ & $5.02 \pm 1.77$ & $3.99 \pm 0.40$ \\
\hline Brain & $0.21 \pm 0.03$ & $0.20 \pm 0.01$ & $0.15 \pm 0.02$ & $0.20 \pm 0.02$ & $0.19 \pm 0.01$ & $0.16 \pm 0.01$ & $0.51 \pm 0.15$ & $0.39 \pm 0.13$ \\
\hline Heart & $0.58 \pm 0.05$ & $0.45 \pm 0.08$ & $0.27 \pm 0.06$ & $0.58 \pm 0.04$ & $0.39 \pm 0.03$ & $0.17 \pm 0.04$ & $33.91 \pm 11.37$ & $35.23 \pm 17.61$ \\
\hline Liver & $0.45 \pm 0.04$ & $0.47 \pm 0.10$ & $0.29 \pm 0.10$ & $0.42 \pm 0.05$ & $0.44 \pm 0.03$ & $0.14 \pm 0.01$ & $38.46 \pm 18.41$ & $19.51 \pm 11.76$ \\
\hline Spleen & $0.65 \pm 0.12$ & $0.55 \pm 0.04$ & $0.36 \pm 0.10$ & $0.64 \pm 0.02$ & $0.50 \pm 0.01$ & $0.45 \pm 0.09$ & $16.26 \pm 8.27$ & $10.85 \pm 2.01$ \\
\hline Lung & $1.05 \pm 0.27$ & $0.78 \pm 0.30$ & $0.40 \pm 0.11$ & $1.14 \pm 0.38$ & $0.67 \pm 0.23$ & $0.44 \pm 0.10$ & $5.40 \pm 1.74$ & $5.88 \pm 2.51$ \\
\hline Kidney & $52.81 \pm 9.34$ & $74.89 \pm 5.27$ & $53.18 \pm 2.95$ & $70.63 \pm 12.11$ & $94.63 \pm 15.45$ & $78.99 \pm 10.94$ & $3.133 \pm 1.12$ & $2.32 \pm 0.46$ \\
\hline Stomach & $0.83 \pm 0.08$ & $1.10 \pm 0.26$ & $0.58 \pm 0.10$ & $0.87 \pm 0.04$ & $1.01 \pm 0.21$ & $0.47 \pm 0.09$ & $5.11 \pm 1.81$ & $3.35 \pm 0.92$ \\
\hline Intestine & $2.85 \pm 1.89$ & $2.03 \pm 0.03$ & $1.73 \pm 0.45$ & $1.45 \pm 1.37$ & $1.01 \pm 0.17$ & $0.75 \pm 0.01$ & $7.37 \pm 3.75$ & $4.67 \pm 2.52$ \\
\hline Muscle & $0.50 \pm 0.05$ & $0.48 \pm 0.04$ & $0.22 \pm 0.07$ & $0.54 \pm 0.04$ & $0.49 \pm 0.06$ & $0.54 \pm 0.12$ & $1.59 \pm 0.31$ & $1.09 \pm 0.44$ \\
\hline Pancreas & $1.02 \pm 0.22$ & $1.20 \pm 0.44$ & $0.88 \pm 0.30$ & $3.04 \pm 0.15$ & $1.37 \pm 0.30$ & $1.29 \pm 0.99$ & $23.89 \pm 6.59$ & $18.90 \pm 9.69$ \\
\hline Bone & $0.39 \pm 0.18$ & $0.26 \pm 0.12$ & $0.30 \pm 0.07$ & $0.43 \pm 0.15$ & $0.37 \pm 0.01$ & $0.16 \pm 0.02$ & $4.26 \pm 1.74$ & $3.77 \pm 1.26$ \\
\hline Tumor & $2.05 \pm 0.12$ & $1.55 \pm 0.13$ & $1.00 \pm 0.17$ & $1.33 \pm 0.21$ & $0.91 \pm 0.25$ & $0.78 \pm 0.21$ & $15.20 \pm 0.28$ & $14.73 \pm 0.30$ \\
\hline
\end{tabular}

\section{Discussion}

Although a large number of studies have confirmed that radiotracers targeting GLP-1R were reliable for NETs especially insulinoma [28-30], rare studies have evaluated the value of such tracers for PHEOs. This present study further demonstrated the relationship between GLP-1R expression and PHEOs.

Due to the lack of specificity of clinical symptoms and signs, and the fact that invasive procedures for PHEOs have the high risk of hypertensive crisis, hemorrhage and tumor cell seeding [6], the diagnosis of PHEOs depends on various imaging methods. However, different imaging modalities have different applicability and almost none of them could satisfy the need of risk stratification of PHEOs. ${ }^{131} \mathrm{I} /{ }^{123} \mathrm{I}$-MIBG and ${ }^{18} \mathrm{~F}$-FDG are clinically preferred radiotracers for the functional imaging of PHEOs. The particular advantages of ${ }^{131} \mathrm{I} /{ }^{123} \mathrm{I}$-MIBG SPECT/CT are the detection of local recurrence, small extra-adrenal PHEOs or multifocal tumors [31, 32]. However, it may result in significant underestimation of metastatic disease with potentially inappropriate management $[15] .{ }^{18} \mathrm{~F}-\mathrm{FDG}$ is the best radiotracer to evaluate metastatic PHEOs in SDHB carriers, offering 100\% sensitivity [33]. ${ }^{18} \mathrm{~F}-\mathrm{FDG}$ has higher resolution, specific activity and applicability compared to ${ }^{131} /{ }^{123} \mathrm{I}-\mathrm{MIBG}$, but lower specificity for PHEOs.

In this study, both PC-12 poorly and highly differentiated tumors could be clearly visualized using microPET with ${ }^{68} \mathrm{Ga}$-NOTA-MAL-Cys ${ }^{39}$-exendin-4 after intravenous injection. The imaging data showed tumor uptake reached a plateau quickly with a high contrast between tumor and background, indicating that GLP-1R PET could be a promising modality for PHEOs detection. The risk stratification of PHEOs is crucial since the five-year survival rates of PHEOs with different degrees of differentiation varies greatly [18]. In this study, the results of microPET and biodistribution showed that the uptake of ${ }^{68} \mathrm{Ga}$-NOTA-MAL$\mathrm{Cys}^{39}$-exendin- 4 was significantly different in PC-12 poorly and highly differentiated tumors. The IHC staining also confirmed the difference of GLP-1R expression in these two groups. However, the microPET of ${ }^{18} \mathrm{~F}-\mathrm{FDG}$ and the biodistribution of ${ }^{131}$ I-MIBG didn't show any significant differences between PC-12 poorly and highly differentiated tumorbearing mice. Taken together, these results indicated that GLP-1R PET might be useful for risk stratification of PHEOs and deserves further exploration.

We synthesized this novel radiotracer ${ }^{68} \mathrm{Ga}$-NOTAMAL-Cys ${ }^{39}$-exendin-4 in this present study and the whole labeling process was completed within $20 \mathrm{~min}$ with a yield of $91.6 \pm 2.8 \%$, which confirmed the advantages of ${ }^{68} \mathrm{Ga}$ again. The results of in vitro cell uptake studies showed that the uptake of ${ }^{68} \mathrm{Ga}$-NOTA-MAL-Cys ${ }^{39}$-exendin-4 could be evidently blocked by excess $\mathrm{Cys}^{39}$-exendin-4, which demonstrated the high specificity of this tracer for GLP-1R expressed in both PC-12 poorly and highly differentiated cells. MicroPET imaging showed that the radioactivity uptake of ${ }^{68} \mathrm{Ga}$-NOTAMAL-Cys ${ }^{39}$-exendin- 4 at 30 min after injection was significantly higher than that of $60 \mathrm{~min}$ and $120 \mathrm{~min}$ in both PC-12 poorly and highly differentiated tumors, which was consistent with the results of biodistribution and pharmacokinetics studies. These results taken together illustrated that ${ }^{68} \mathrm{Ga}$-NOTA-MAL-Cys ${ }^{39}$-exendin- 4 was rapidly concentrated in tumor and could be cleared quickly in vivo.

This study also has some limitations. From the microPET and biodistribution studies we can see that the uptake of radioactivity in kidney was much higher than other organs. High radioactivity in kidney implied the tracer was primarily eliminated by the kidney. However, this may cause unnecessary radiation in kidney and influence the potential utility of this radiotracer [21]. In fact, high uptake of radioac- 
tivity in kidney is hard to avoid in almost all radiolabeled exendin-4, including ${ }^{18} \mathrm{~F},{ }^{64} \mathrm{Cu},{ }^{111} \mathrm{In},{ }^{99 \mathrm{~m}} \mathrm{Tc}$ and ${ }^{68} \mathrm{Ga}$ labeled GLP-1 analogs $[24,34]$. We have conducted a series of experiments to optimize radiolabeled GLP-1 analogs in order to reduce the radioactivity in kidney, including trying more precursors, making other modifications to GLP-1 analogs, and comparing different radionuclides and more experiments are currently underway. Another limitation is that we didn't directly compare the imaging differences between GLP-1R PET and ${ }^{131}$ I-MIBG SPECT. However, it has been recognized that the resolution of PET is higher than that of SPECT, and the biodistribution results in this study have been sufficient to demonstrate that ${ }^{131}$ I-MIBG was unable to identify PC-12 poorly and highly differentiated tumors while ${ }^{68} \mathrm{Ga}$-NOTA-MAL-Cys ${ }^{39}$-exendin-4 could fulfill this requirement. Finally, the risk stratification of PHEOs in this study was initially based on poor and high differentiation. More studies are needed to establish a more precise association between GLP-1R PET imaging, GLP-1R expression and the risk stratification of PHEOs.

In this study, we synthesized a novel radiotracer ${ }^{68} \mathrm{Ga}-\mathrm{NOTA}-\mathrm{MAL}-\mathrm{Cys}^{39}$-exendin-4 that specifically target GLP-1R and demonstrated that GLP-1R PET can be used in the diagnosis of PHEOs with high specificity and good image contrast. In addition, we confirmed that GLP-1R PET might have potential for the risk stratification of PHEOs.

Acknowledgements: This work was partially supported by National Key Research and Development Program of China (2016YFC1306600 and 2017ZX09304021), National Natural Science Foundation (31671035), Jiangsu Provincial Medical Innovation Team (CXTDA2017024), Jiangsu Province Foundation (BE2016632), Jiangsu Provincial Commission of Health and Family Planning Foundation (LGY2017088, QNRC2016628, and H2017031), and Wuxi International R \& D Cooperation Projects (WX0303B010518180012PB).

\section{References}

[1] JIMENEZ C, ROHREN E, HABRA MA, RICH T, JIMENEZ $\mathrm{P}$ et al. Current and future treatments for malignant pheochromocytoma and sympathetic paraganglioma. Curr Oncol Rep 2013; 15: 356-371. https://doi.org/10.1007/s11912-0130320-x

[2] TOLEDO RA, BURNICHON N, CASCON A, BENN DE, BAYLEY JP et al. Consensus Statement on next-generationsequencing-based diagnostic testing of hereditary phaeochromocytomas and paragangliomas. Nat Rev Endocrinol 2017; 13: 233-247. https://doi.org/10.1038/nrendo.2016.185

[3] ZARNEGAR R, KEBEBEW E, DUH QY, CLARK OH. Malignant pheochromocytoma. Surg Oncol Clin N Am 2006; 15: 555-571. https://doi.org/10.1016/j.soc.2006.05.009

[4] HARARI A, INABNET WB, 3rd. Malignant pheochromocytoma: a review. Am J Surg 2011; 201: 700-708. https://doi. org/10.1016/j.amjsurg.2010.04.012
[5] CHEN H, SIPPEL RS, O'DORISIO MS, VINIK AI, LLOYD RV et al. The North American Neuroendocrine Tumor Society consensus guideline for the diagnosis and management of neuroendocrine tumors: pheochromocytoma, paraganglioma, and medullary thyroid cancer. Pancreas 2010; 39: 775-783. https://doi.org/10.1097/MPA.0b013e3181ebb4f0

[6] VANDERVEEN KA, THOMPSON SM, CALLSTROM MR, YOUNG WF, Jr, GRANT CS et al. Biopsy of pheochromocytomas and paragangliomas: potential for disaster. Surgery 2009; 146: 1158-1166. https://doi.org/10.1016/j. surg.2009.09.013

[7] CHEN Y, XIAO H, ZHOU X, HUANG X, LI Y et al. Accuracy of plasma free metanephrines in the diagnosis of pheochromocytoma and paraganglioma: A systematic review and meta-analysis. Endocr Pract 2017; 23: 1169-1177. https:// doi.org/10.4158/EP171877.OR

[8] ZUO M, ZHEN Q, ZHANG X, ZOU W, YANG X et al. High specificity of spot urinary free metanephrines in diagnosis and prognosis of pheochromocytomas and paragangliomas by HPLC with electrochemical detection. Clin Chim Acta 2018; 478: 82-89. https://doi.org/10.1016/j.cca.2017.12.026

[9] MERCADO-ASIS LB, WOLF KI, JOCHMANOVA I, TAIEB D. Pheochromocytoma: A genetic and diagnostic update. Endocr Pract 2018; 24: 78-90. https://doi.org/10.4158/EP2017-0057

[10] FARRUGIA FA, MARTIKOS G, TZANETIS P, CHARALAMPOPOULOS A, MISIAKOS E et al. Pheochromocytoma, diagnosis and treatment: Review of the literature. Endocr Regul 2017; 51: 168-181. https://doi.org/10.1515/ enr-2017-0018

[11] CASTINETTI F, KROISS A, KUMARR, PACAK K, TAIEB D. 15 years of paraganglioma: Imaging and imaging-based treatment of pheochromocytoma and paraganglioma. Endocr Relat Cancer 2015; 22: T135-145. https://doi. org/10.1530/ERC-15-0175

[12] BALOGOVA S, TALBOT JN, NATAF V, MICHAUD L, HUCHET $\mathrm{V}$ et al. 18F-fluorodihydroxyphenylalanine vs other radiopharmaceuticals for imaging neuroendocrine tumours according to their type. Eur J Nucl Med Mol I 2013; 40: 943-966. https://doi.org/10.1007/s00259-013-2342-x

[13] WANG H, CHENG Y, ZHANG J, ZANG J, LI H et al. Response to single low-dose 177Lu-DOTA-EB-TATE treatment in patients with advanced neuroendocrine neoplasm: A prospective pilot study. Theranostics 2018; 8: 3308-3316. https://doi.org/10.7150/thno.25919

[14] DEPPEN SA, BLUME J, BOBBEY AJ, SHAH C, GRAHAM $\mathrm{MM}$ et al. 68Ga-DOTATATE compared with 111In-DTPAOctreotide and conventional imaging for pulmonary and gastroenteropancreatic neuroendocrine tumors: A systematic review and meta-Analysis. J Nucl Med 2016; 57: 872-878. https://doi.org/10.2967/jnumed.115.165803

[15] TAIEB D, TIMMERS HJ, HINDIE E, GUILLET BA, NEUMANN HP et al. EANM 2012 guidelines for radionuclide imaging of phaeochromocytoma and paraganglioma. Eur J Nucl Med Mol I 2012; 39: 1977-1995. https://doi. org/10.1007/s00259-012-2215-8 
[16] HAMIDI O, YOUNG WF, Jr., INIGUEZ-ARIZA NM, KITTAH NE, GRUBER L et al. Malignant pheochromocytoma and paraganglioma: 272 patients over 55 years. J Clin Endocrinol Metab 2017; 102: 3296-3305. https://doi.org/10.1210/ jc.2017-00992

[17] KIMURA N, TAKAYANAGI R, TAKIZAWA N, ITAGAKI E, KATABAMI T et al. Pathological grading for predicting metastasis in phaeochromocytoma and paraganglioma. Endocr Relat Cancer 2014; 21: 405-414. https://doi.org/10.1530/ ERC-13-0494

[18] KIMURA N, TAKEKOSHI K, NARUSE M. Risk stratification on pheochromocytoma and paraganglioma from laboratory and clinical medicine. J Clin Med 2018; 7. https://doi. org/10.3390/jcm7090242.

[19] HUBALEWSKA-DYDEJCZYK A, SOWA-STASZCZAK A, TOMASZUK M, STEFANSKA A. GLP-1 and exendin-4 for imaging endocrine pancreas. A review. Labelled glucagonlike peptide-1 analogues: past, present and future. Q J Nucl Med Mol Imaging 2015; 59: 152-160.

[20] XU Y, PAN D, XU Q, ZHU C, WANG L et al. Insulinoma imaging with glucagon-like peptide-1 receptor targeting probe (18)F-FBEM-Cys (39)-exendin-4. J Cancer Res Clin 2014; 140: 1479-1488. https://doi.org/10.1007/s00432-0141701-8

[21] XU Q, ZHU C, XU Y, PAN D, LIU P et al. Preliminary evaluation of [18F]AlF-NOTA-MAL-Cys39-exendin-4 in insulinoma with PET. J Drug Target 2015; 23: 813-820. https://doi. org/10.3109/1061186X.2015.1020808

[22] MI B, XU Y, PAN D, WANG L, YANG R et al. Non-invasive glucagon-like peptide-1 receptor imaging in pancreas with 18F-Al labeled Cys39-exendin-4. Biochem Biophys Res Commun 2016; 471: 47-51. https://doi.org/10.1016/j. bbrc.2016.01.184

[23] YUE Y, XU Y, HUANG L, PAN D, BAI Z et al. Evaluation of a novel GLP-1R ligand for PET imaging of prostate cancer. Anticancer Agents Med Chem 2019; 19: 509-514 https://doi. org/10.2174/1871520618666180801101730

[24] LUO Y, PAN Q, YAO S, YU M, WU W et al. Glucagon-like peptide-1 receptor PET/CT with 68Ga-NOTA-exendin-4 for detecting localized insulinoma: A prospective cohort study. J Nucl Med 2016; 57: 715-720. https://doi.org/10.2967/ jnumed.115.167445

[25] WANG L, LIU Y, XU Y, SHENG J, PAN D et al. Age-related change of GLP-1R expression in rats can be detected by [18F] AlF-NOTA-MAL-Cys39-exendin-4. Brain Res 2018; 1698: 213-219. https://doi.org/10.1016/j.brainres.2018.08.022
[26] VAIDYANATHAN G, ZALUTSKY MR. No-carrier-added synthesis of meta-[131I]iodobenzylguanidine. Appl Radiat Isot 1993; 44: 621-628. https://doi.org/10.1016/09698043(93)90179-e

[27] XU Y, PAN D, ZHU C, XU Q, WANG L et al. Pilot study of a novel 18F-labeled FSHR probe for tumor imaging. Mol Imaging Biol 2014; 16: 578-585. https://doi.org/10.1007/ s11307-013-0712-1

[28] ANTWI K, FANI M, HEYE T, NICOLAS G, ROTTENBURGER $\mathrm{C}$ et al. Comparison of glucagon-like peptide-1 receptor (GLP-1R) PET/CT, SPECT/CT and 3T MRI for the localisation of occult insulinomas: evaluation of diagnostic accuracy in a prospective crossover imaging study. Eur J Nucl Med Mol I 2018; 45: 2318-2327. https://doi.org/10.1007/ s00259-018-4101-5

[29] CHRIST E, WILD D, EDERER S, BEHE M, NICOLAS G et al. Glucagon-like peptide-1 receptor imaging for the localisation of insulinomas: a prospective multicentre imaging study. Lancet Diabetes Endocrinol 2013; 1: 115-122. https:// doi.org/10.1016/S2213-8587(13)70049-4

[30] WU Z, LIU S, NAIR I, OMORI K, SCOTT S et al. 64Cu labeled sarcophagine exendin- 4 for microPET imaging of glucagon like peptide-1 receptor expression. Theranostics 2014; 4: 770-777. https://doi.org/10.7150/thno.7759

[31] GIMM O, DEMICCO C, PERREN A, GIAMMARILE F, WALZ MK et al. Malignant pheochromocytomas and paragangliomas: a diagnostic challenge. Langenbecks Arch Surg 2012; 397: 155-177. https://doi.org/10.1007/s00423-0110880-x

[32] FUKUOKA M, TAKI J, MOCHIZUKI T, KINUYA S. Comparison of diagnostic value of 123I MIBG and high-dose 131I MIBG scintigraphy including incremental value of SPECT/CT over planar image in patients with malignant pheochromocytoma/paraganglioma and neuroblastoma. Clin Nucl Med 2011; 36: 1-7. https://doi.org/10.1097/ RLU.0b013e3181feeb5e

[33] TIMMERS HJ, KOZUPA A, CHEN CC, CARRASQUILLO JA, LING A et al. Superiority of fluorodeoxyglucose positron emission tomography to other functional imaging techniques in the evaluation of metastatic SDHB-associated pheochromocytoma and paraganglioma. J Clin Oncol 2007; 25: 2262-2269. https://doi.org/10.1200/JCO.2006.09.6297

[34] KIESEWETTER DO, GAO H, MA Y, NIU G, QUAN Q et al. 18F-radiolabeled analogs of exendin-4 for PET imaging of GLP-1 in insulinoma. Eur J Nucl Med Mol I 2012; 39: $463-$ 473. https://doi.org/10.1007/s00259-011-1980-0 